\title{
The Impact of Firm Size and E-commerce Usage on Business Performance on Hospitality Industry: A case of Libya \\ Mohamed Ahmed A.Said
}

Faculty of Technology University Malaysia Pahang

Mohamedsaid2706@gmail.com

PROF. MADYA. DR. NOOR AZLINNA BINTI AZIZAN

Faculty of Technology University Malaysia Pahang

\section{Abstract}

$$
\text { azlinna@ump.edu.my }
$$

\begin{abstract}
The hospitality industry is major service sector in most of developed and developing countries in the world economy, and nowadays many hotels implemented e-commerce for their business models and gained great advantages and increase profitability. This study aims to examine the impact of firm size and e-commerce usage on business performance of hospitality industry in general and hotels in Libya in particular. A quantitative approach was applied on hotel industry in Libya, mainly those hotels that have previous practices and experience with e-commerce. The results shows that small and medium size firms in hospitality industry in Libya are facing similar challenges and obstacles to other small businesses when establishing e-commerce website, and also shows a strong relationship between e-commerce usage and business performance, and high increase in profitability when hotels implement e-commerce and start to conduct online booking
\end{abstract}

Keywords: E-commerce usage, Business Performance, Firm Size, Hospitality Industry

\section{Council for Innovative Research}

Journal: INTERNATIONAL JOURNAL OF COMPUTERS \& TECHNOLOGY

Vol 13, No. 3

editor@cirworld.com

www.cirworld.com, www.ijctonline.com 


\section{Introduction}

E-commerce is a booming business technology, and the fast growing globalization and the emerging of new markets have made modern organization aware of the necessity to operate effectively on the internet in a very competitive international environment. Currently, concepts such as e-business or e-commerce have found their place and applicability inside the global economy with ease, knowing it promoted models exhibiting an accelerated rate of development, well above the usual average growing rate of the traditional economy (Silviu, 2011).

The Internet has consolidated itself as a very powerful platform that has changed the way of communication between sellers and buyers, and the way of doing business. Over the last decade the population of internet users has increased rapidly. E-commerce mainly helps in the generation of leads, presenting information about the tourism product to the customers, and facilitating the transaction process electronically mainly using the World Wide Web. Thus hotels in all over the world expected to achieve significant benefits and higher profits through the increasing utilization of the internet technology for their business.

The hospitality industry has always been among the first to capitalize on new technologies. Costumers are constantly seeking new sources of information to help them make decisions before booking for accommodation and hospitality services. With implementing e-commerce for hotel industry, the landscape of the hospitality industry is forever changed. Nowadays online sales are an important part to hospitality business that can't afford be to ignore in the current competitive market because of globalization. In addition to that the growing importance of e-commerce in the modern hospitality industry has created an urgent need for evaluation the main factors that affect companies' online presence, therefore smart hoteliers need to keep a sharp focus on the fundamental shift in ways customers are seeking information and channels that drive maximum return on investment.

It was that firm size has been widely examined as an influential factor in the literature of diffusion of innovation (Damanpour, 1991; Zhu et al., 2004), where large firms are more likely to benefit from using e-commerce technology comparing to small firms (Salwani et al., 2009; Sahadev \& Islam, 2005). Moreover, e-commerce usage for communicating and transacting with customers has been growing rapidly in the worldwide tourism industry. However, there is a large variation in the intensity of use of e-commerce in the travel and tourism industry. While the Internet usage varies across countries, even within a country there are large variations amongst enterprises (Hoontrakul \& Sahadev, 2005).

\section{The purpose of this study}

This study aims to examine the impact of firm size and e-commerce usage on business performance of hospitality industry in general and hotels in Libya in particular. The study attempt to understand why small and medium size businesses in hotel industry facing big challenges comparing to big size hotels. In addition to that the study evaluates the effect of ecommerce usage in improving the business performance of hotels and increase profits.

\section{The Contribution of the study}

The study will provide valued information on the relationship between e-commerce usage and business performance by evaluating the effect of firm size on the performance of companies working in hospitality industry and its relationship with e-commerce implementation. The study will contribute the literature of electronic commerce and help small size firms working in hospitality industry to develop their business online effectively. The findings of this study would facilitate Libyan hotels to move towards venture into e-commerce initiatives in many ways. An analysis of various factors that predict the technology usage may be useful in improving the rate of implementation and success

\section{The problem Statement}

The question of how and whether using e-commerce in tourism sector creates new value to business performance in this sector has always being the factor considered by many companies before they start to transfer their business model to electronic business. This question is not being asked by big companies, nowadays most small and medium size companies started to initiate business model online through e-commerce usage.

Rapid development in marketing using internet technology is attracting huge interests of both service providers and customers, and with the strong presence of globalization, most of companies realized the great importance of e-commerce usage on their business. However, there is agreement among many scholars that the hospitality industry has not been able to manage very well with all the challenges and the high competition in the global market because of globalization and increasing rate of e-commerce adoption by hotels in developed and developing countries, while in Libya the management of hotels are still not paying high attention to implementing e-commerce for their business model and could not realize the strong potential of the booming technology.

Therefore, this study discusses the problem associated with the factors that affect business performance and attempt to know how e-commerce usage develop business performance of Libyan hotels and attempt to solve the problems facing small and medium size hotel to implement e-commerce effectively

\section{The research questions}

1. What are the factors that influence the level of e-commerce usage and business performance of hotels in Libya?

2. How firm size and e-commerce usage correlated in improving business performance? 
3. Why big size firms are more capable to use e-commerce and acquire greater business advantage from ecommerce?

\section{The Methodology}

The study applied a quantitative approach, and was conducted through a questionnaire survey on hotels industry in Libya, in particular those hotels that have previous practices and experience with e-commerce. The target population for this study consists of hotels in Libyan tourism sector. The sampling frame for this study will be drawn from the list of hotels companies registered with the ministry of tourism in Libya. The number of distributed questionnaires equal to 200 , including a cover letter submitted to the participants. The questionnaire directed to the sales or marketing managers, who is involved in the process relating to e-commerce operation and usage.

\section{Firm Size and E-commerce Adoption}

E-commerce is an unfolding phenomenon in technology advancement. Most large firms are still at the infancy stage of positioning themselves to exploit business opportunities enabled by the Internet (Zhu, 2004). It is difficult to determine the best measures of e-commerce capabilities. These points to the need for the development of an interactive, comprehensive and multidimensional theoretical model that may offer guidance in measuring e-commerce impact on firm's performance.

It has been found that the size of the organization can influence the decision to adopt or not to adopt e-commerce (Thong, 1999; Bharati \& Chaudhury, 2006). A small firm will find it very challenging to acquire e-commerce due to the high cost of set up, and the impact of size has generally been found to be an insignificant influence on e-commerce adoption (Karakaya \& Shea, 2008), possibly because the playing field has been levelled with better and easier logistics to deploy ecommerce systems.

With the advent of e-commerce, organizations have had to rethink in their investment and acquisition decisions due to the strategic nature of electronic commerce, and the existence of high levels of significance between the size of the business and customer demand, reduced costs, developing new markets and improvement to marketing as driving forces, and the type of business and customer demand, pressure from competition, increased sales and improvement of relationship with business partners as driving forces for e-commerce adoption (Magnusson et al., 2002).

Small and medium size firms working in hospitality industry tended to target interstate and local tourists, whereas their urban counterparts were more likely to target overseas visitors. This has an impact on how their offerings are marketed online (Davidson \& Burgess, 2006) and the finds the following:

- Most of the businesses interviewed had been operating a website for a while, with the majority indicating between three and five years. A few businesses had set up the website at the same time they started their businesses because of financial inability.

- The primary reason for setting up the websites was to provide information and as part of an overall promotion strategy. This was consistent with most small businesses. Unfortunately websites were typically updated between six months and one year, or when a major business change occurred.

- Approximately half of the businesses considered cost and employee skill levels and fewer considered the skill level of employees before setting up the website, and about two thirds considered their customers' needs but only around one half looked at what their competitors were doing.

- $\quad$ There was little evidence of integration with existing systems (e.g. booking systems) and the website. The results of this scoping study indicated that there was a real need for small hotels to be encouraged to develop appropriate planning approaches to the development of their website systems. Present approaches indicated a lack of basic business planning and strategy formation techniques which made the end result more of a matter of chance than a systematically planned outcome.

According to above, investing in new technologies has a risky nature; this may prompt small hotels to wait before investing in the new technology until the technology has stabilized (Sahadev \& Islam, 2005), and although the primary motive of businesses is profit, the impacts on the local economy will vary according to their size. In the hospitality literature, there is a variety of studies which have research aspects of development for small firms (e.g. Beaver \& Lashley, 1998; Friel,1999 Getz \& Carlsen, 2000). However, there is limited research for larger hospitality firms. The reason for this may be that the hospitality industry tends to be dominated by a large number of small firms operating alongside a few large ones (Shaw \& Williams, 1994).

Based on the above; this study assumes that "Firm Size has a positive relationship for e-commerce adoption and business performance", and attempts to verify this hypothesis in the following analysis.

\section{E-commerce Usage and Business Performance}

Increase the competition in the hotel industry in recent years has attracted more attention on the performance of hotels (Yu \& Lee, 2009). The performance of a hotel includes many dimensions, and the evaluation of each dimension may lead to different managerial decisions (Sun \& Lu, 2005). Some researchers have emphasized on the factors that influence on hotel performance, such as such as human resource management, internet usage and internal marketing. These studies presented factors influencing hotel performance and some indicators to measure hotel performance (Yu and Lee, 2009). Organizations evaluate their innovations through the positive impact of e-commerce usage on their performance, comparing to the other organizations that don't use e-commerce technology (Salwani et al., 2009). This is because that organizations use e-commerce technology to improve their performance (Zhu and Kraemer, 2005), for 
example in a study that conducted in china showed that Chinese business managers considered that e-business usage cannot be successful until it provides real benefits to improve the organizational performance (Wua et al., 2011), and using survey data from 152 Chinese firms and their B2B e-business systems, they found that systems development and systems usage having a positive impact on organizational performance, while Rosenzweig (2009) in his study using a sample of 50 U.S. firms, he proved empirically that e-commerce usage affect positively and significantly on business performance. Sanders, (2007) proposed a model of the relationship between usage of e-business technologies, organizational collaboration, and performance, using empirical data from a survey of $245 \mathrm{U}$.S firms; she found that usage of e-business technologies affects both directly and indirectly on firms performance. Further she call for more researches to investigate the relationship between e-business technology and performance in the context of services. In the context of tourism services, Kim et al., (2011) concluded that tourism services' performance for tourism online shopping improved through usage B2C e-commerce in Korea, while Alsharayri (2011) based on empirical study which included a sample of (100) accountant on (10) five and four stars hotels in Jordan, he found that e-commerce usage can improve accounting information system in hotels, which in turn will lead to improve hotels performance significantly, these results shows that hotel firms' investments in IT applications can lead to superior IT capabilities and high improvement in business performance, which in turn lead to decrease cost, increase agility and innovation, in addition to added value for customers, and improve customer service (Bilgihan et al., 2011).

Daghfous and Barkhi,(2009) based on survey of 100 four-and five-star hotels in the UAE found hotels with a formal IT/IS strategy are more likely to achieve higher service quality and operational efficiency, which in turn will lead to higher overall performance.

In order to investigate the effect of e-commerce usage on business performance in Libyan hotels, this study assumes that "e-commerce usage has a positive influence on Business performance", and attempts to verify this hypothesis in the following analysis.

\section{Discussion and Analysis}

In the following section, the study analyzes the primary data collected from the participants in the survey made for evaluating the impact of firm size and e-commerce usage on business performance.

The target population for this analysis consists of hotels in Libyan tourism sector. The participants represent the employees in the hotel industry and applies a structural equation modeling (SEM) as a primary data analysis technique. The sampling frame for this study has been drawn from the list of hotels companies registered with the ministry of tourism in Libya. The number of participants is 80 from overall 200 questionnaire distributed.

\subsection{Firm Size}

The size of firm is supposed to correlate with its performance and also the capability to implement online business. Large firm also are likely to be more developed than small firms, this allows larger firms to pursue and respond more quickly than smaller firms to the technological usage opportunities (Sarkees, 2011). Given this, to investigate the effect of firm size on e-commerce' usage in Libyan hotels.

This study assumes that "Firm Size has a positive relationship for e-commerce adoption and business performance", therefore the study investigates this hypothesis through the following phrases:

\subsubsection{The capital of my hotel is higher compared to the industry.}

We asked the participants about their opinion with regard to the financial capital of the hotel and its relationship to the hospitality industry.

The results showed that (4 strongly disagree, 20 disagree, 34 neutral, 21 agree, 1 strongly agree). The results statistics is shown in Figure-1 below: 


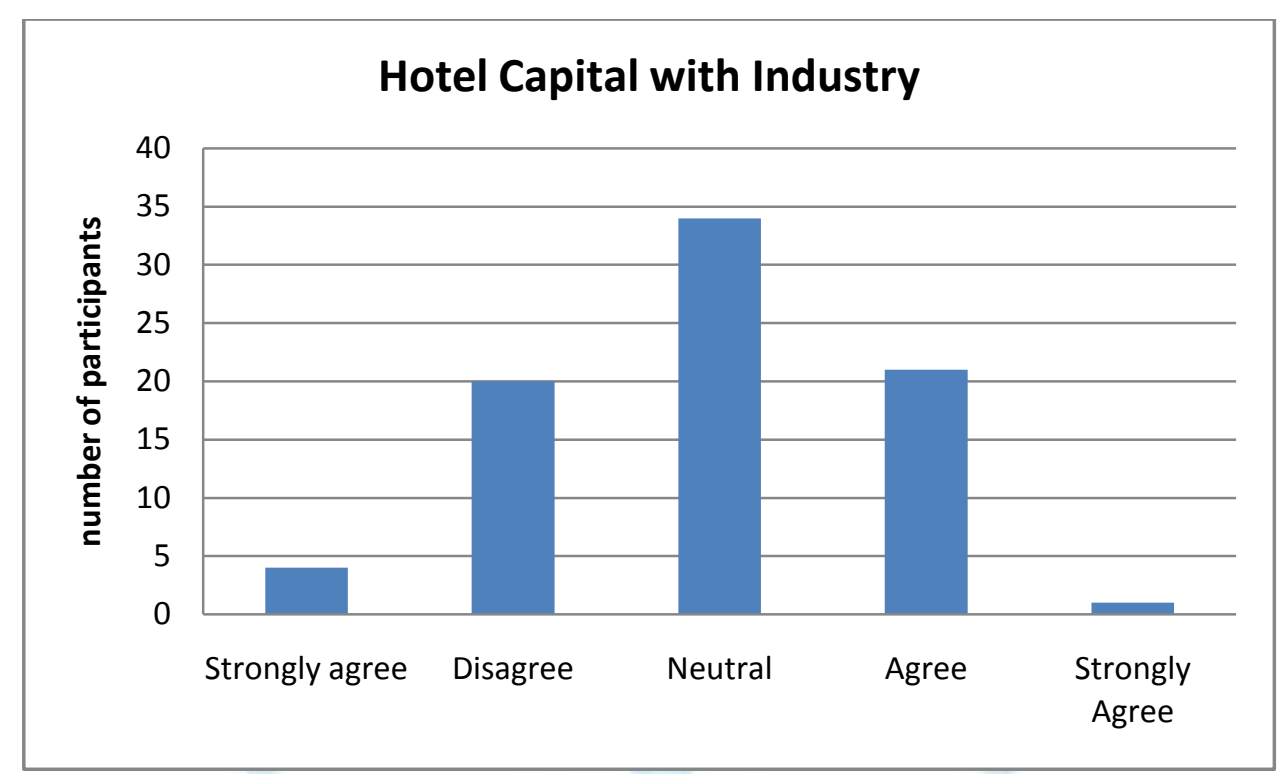

Figure-1: Shows the hotel capital with hospitality industry

The result shows that participants are not sure whether the hotel need for high capital or not to cope with the demand of the industry. The mean value (2.9375) shows that the study population cluster near the Neutral opinion, where the uncertainty of the industry demand for hotel capital, Standard deviation is high (0.87647), which means variation from the mean is high, and other participants are tend distract in their opinion.

This result identical with the results recently obtained for a large sample of Dutch firms in the hospitality industry - the study examines whether the assumption that growth rates of industry are independent of firm size can be rejected for the hospitality services, as it has been for manufacturing, also in the case of Italy. Based on a large sample of Italian newborn firms in five business groups in the hospitality industry, the evidence suggests that growth rates are, in fact, independent of firm size in two business groups (Piergiovanni, 2005), while Andriotis (2002) concludes that the smaller the size of hospitality firm the larger the benefits to the local economy, and there is a growing consensus that hospitality firms' size has important influences on the economic development of a destination there has been a comparative neglect of tourism research into this issue.

\subsubsection{The revenue of my hotel is high compared to the industry.}

We asked the participants about their opinion with regard to the annual revenue of the hotel and its relationship to hospitality business.

The results showed that ( 0 strongly disagree, 2 disagree, 47 neutral, 28 agree, 3 strongly agree). The results statistics is shown in Figure-2 below:

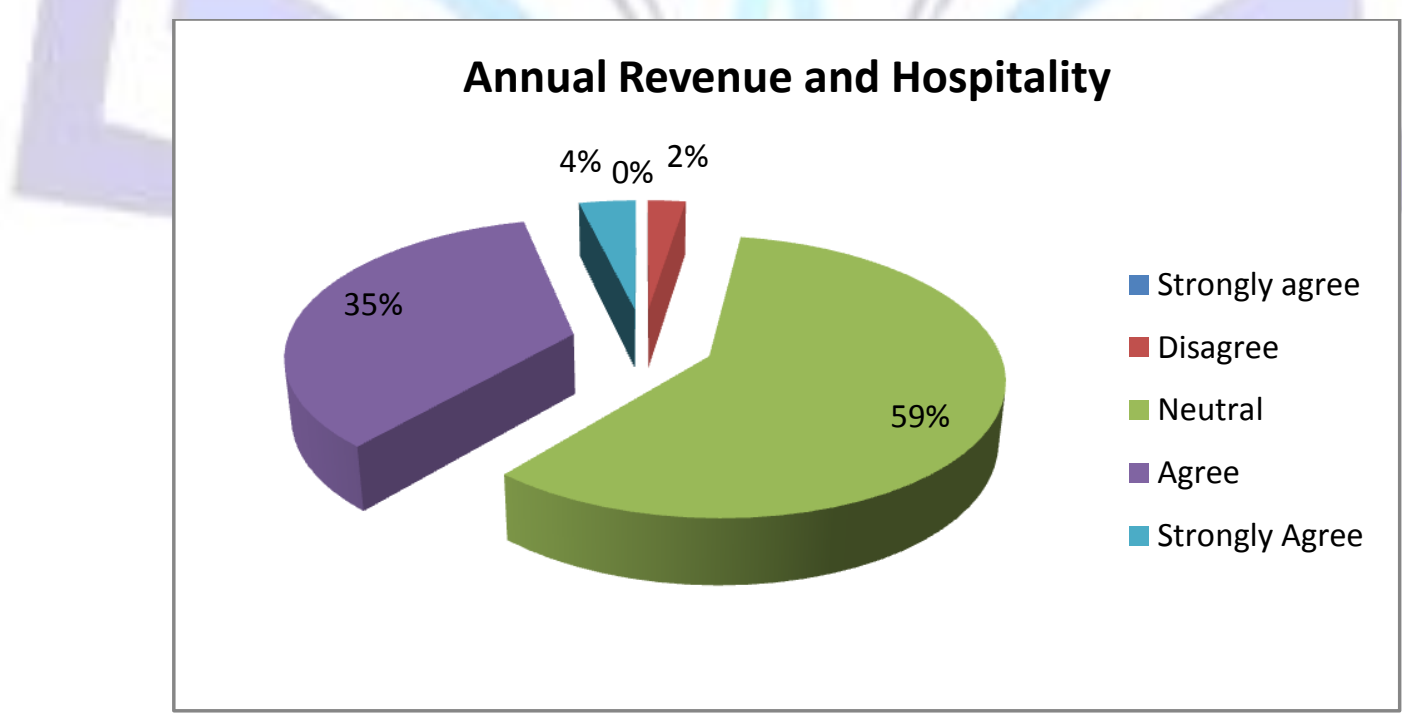

Figure-2: Shows relationship between the annual revenue and hospitality industry.

The result shows that $59 \%$ of participants have no certain opinion about the relationship between hotel revenue and hospitality business, while $35 \%$ of participant agree that when the hospitality business grows the annual revenue become high, this conclusion is identical with the obtained mean value $(3.4000>3)$, which means that the study population tends to 
agree more than neutral opinion. And since the standard deviation equal (0.60796), which is relatively small, it means that the other opinions tends to cluster near to the mean value.

We conclude from this result that there is a positive relationship between the firm size and its business revenue, in particular in hospitality industry. In 2011 in the United States, the hotel industry generated $\$ 21.6$ billion in pretax income, a $20 \%$ increase in year-over-year comparisons. Total industry revenue increased to $\$ 137.5$ billion from $\$ 127.7$ billion in 2010; the largest percentage change in the last ten years (U.S. Department of Commerce, 2012)

\subsubsection{The number of employees at my hotel is higher compared to the industry}

The hospitality industry is major service sector in most of developed and developing countries in the world economy. The industry includes an extensive variety of service industries, mainly accommodation and hotels. Hospitality industry suffers from revenue fluctuations within an economy every year, and therefore the management of Libyan hotels should measure the industry demand and understand that high quality hospitality industry is characterized by a large number of employees.

We asked the participants about their perspective about the relationship of the number of employees with hospitality market demand.

The results showed that ( 5 strongly disagree, 37 disagree, 36 neutral, 2 agree, 0 strongly agree). The results statistics is shown in Figure-3 below:

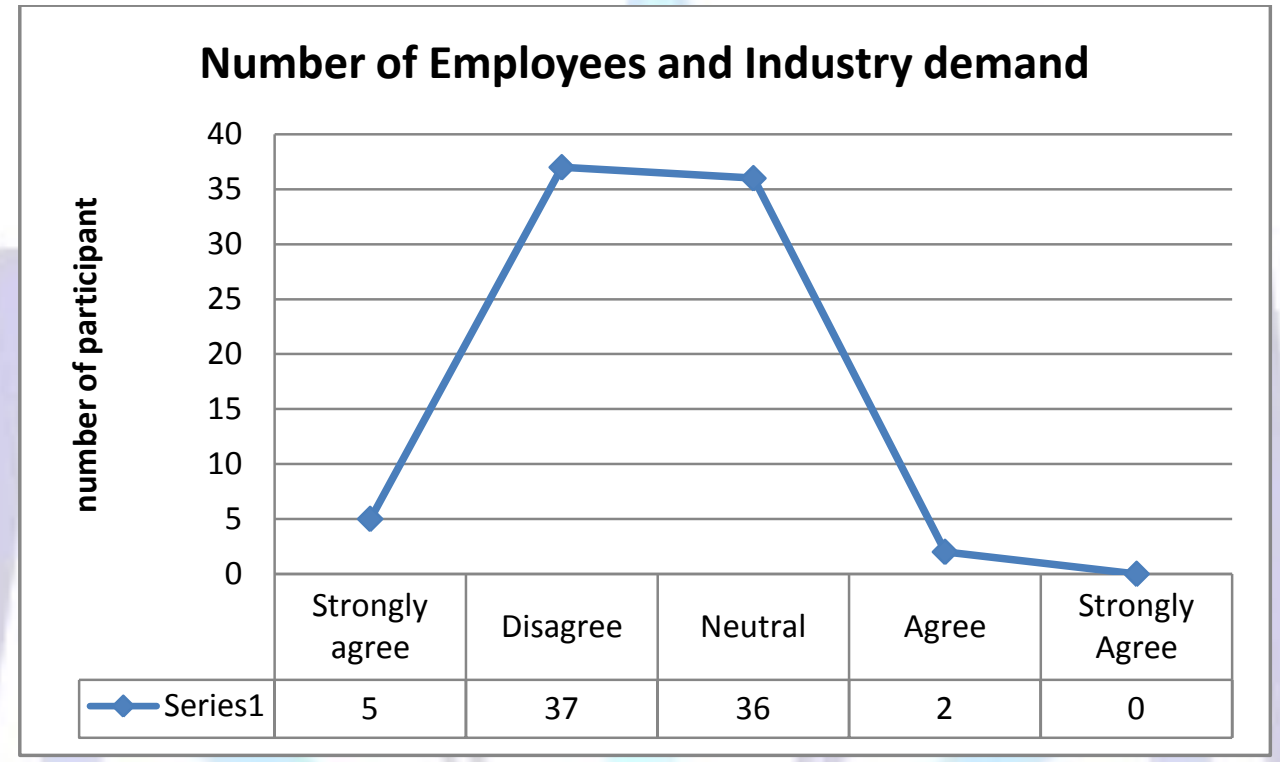

Figure-3: Number of Employees in the company and its relationship with industry demand

As shown from Figure-3 above that the majority of participants either does not agree or not decided that the number of employees working in Libyan hotels is enough to cope with the actual demand of hospitality industry. The percentage of participants those who disagree and strongly disagree equal to $52.50 \%$, which means there is a lack of staff and human resources in hospitality industry in Libya. This result is identical with the mean (2.4375) and a small standard deviation (0.65301), which increase the reliability of our conclusion that Libyan hotels need for more employees to improve the performance of work, also adopting e-commerce in hotel business will increase the demand on accommodation in Libyan hotels, therefore these hotels need for more working staff in order to provide efficient service to prospect clients.

\subsection{E-commerce Usage}

E-commerce applications enable firms from different types of industry to establish their presence in the market at national level and also to extend their economic activities beyond national borders in order to pursue opportunities elsewhere. The usage of e-commerce has the potential to reshape the performance of firms working in the hospitality industry, and effective e-commerce usage enabling price and service-related comparisons in a borderless market environment (Frieden et al., 2006)

In this section we investigate the impact of e-commerce usage on the business performance. The study assumes that " $e$ commerce usage has a positive influence on Business performance", therefore the study investigates this hypothesis through the following phrases:

\subsubsection{Percentage of sales to businesses conducted online}

We asked the participants about their opinion with regard to the percentage of sales in their business place.

The results showed that ( 0 strongly disagree, 0 disagree, 6 neutral, 46 agree, 28 strongly agree). The results statistics is shown in Figure-4 below: 


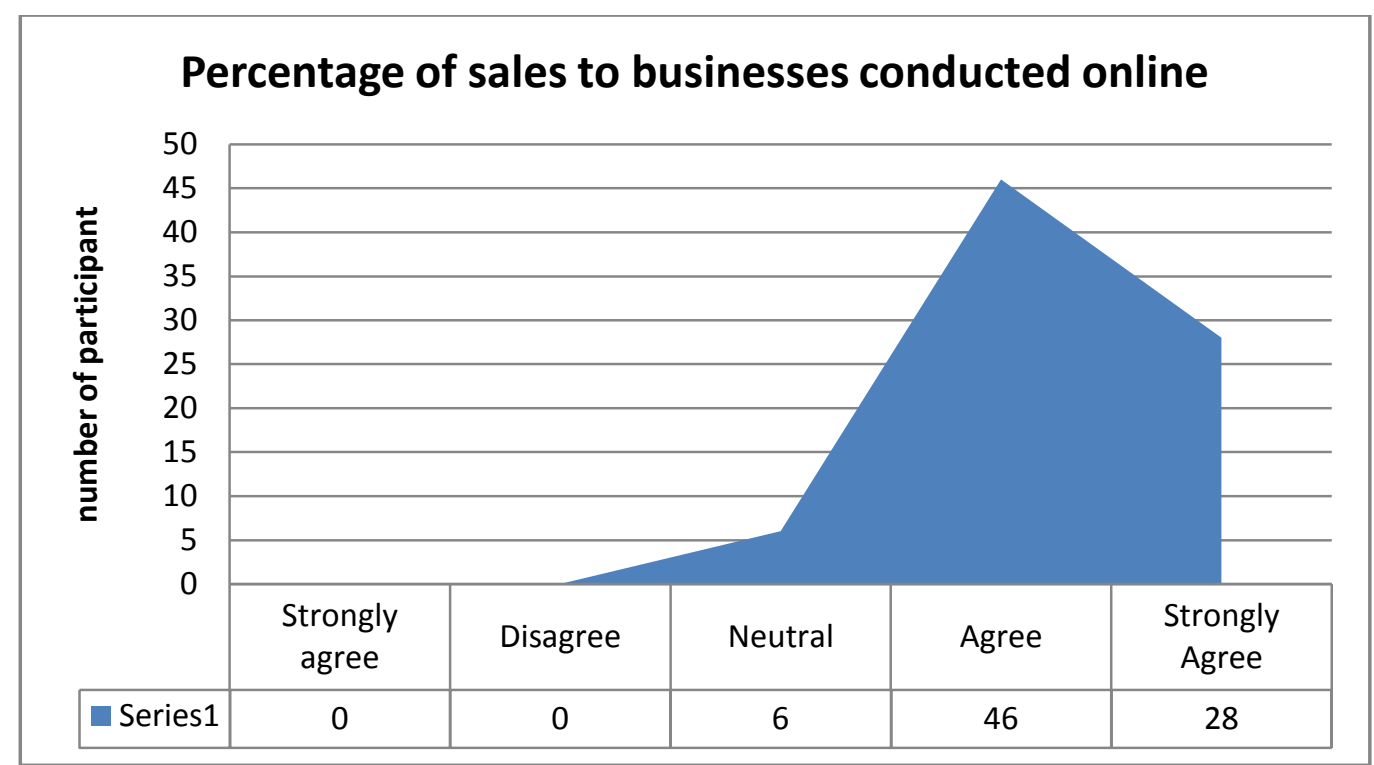

Figure-4: The Percentage of sales to businesses conducted online

Figure-4 above shows that the vast majorities (92.50\%) of participants agree and strongly agree that adopting ecommerce by their hotels will increase the percentage of sales. The mean $(4.2750>4)$ shows that the study population is highly agree and emphasize on the importance of e-commerce to increase the sales volume of hospitality industry. In addition to that, standard deviation value $(0.59481)$ is small, which means that the opinion's of participants cluster very close near to the mean value.

\subsubsection{Percentage of sales to consumers conducted online}

We asked the participants about their opinion with regard to the percentage of consumers usage to e-commerce website of hotels, and its impact on sales volume.

The results showed that ( 0 strongly disagree, 0 disagree, 7 neutral, 44 agree, 29 strongly agree). The results statistics is shown in Figure-5 below:

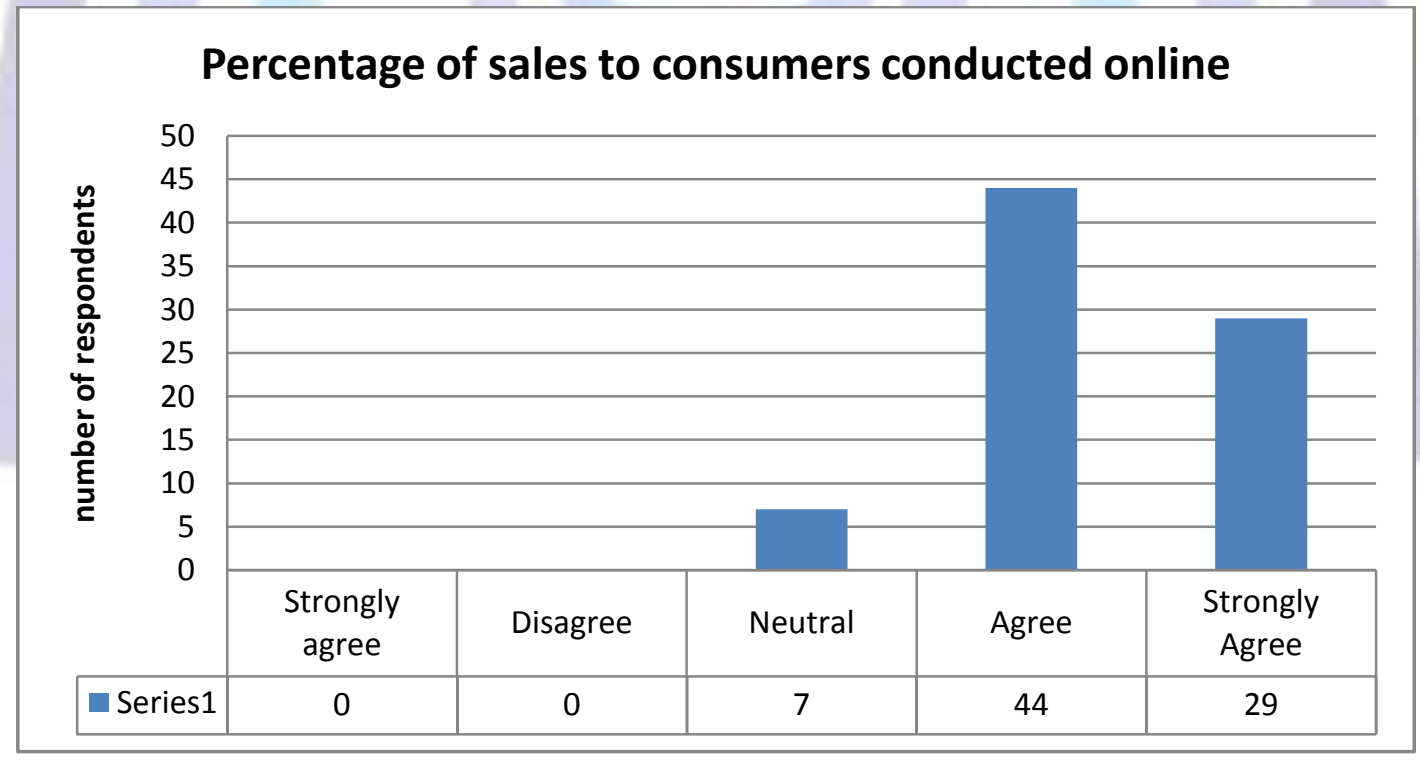

Figure-5: Percentage of sales to consumers conducted online

The result shown in Figure- 5 above is identical with the previous question and indicates that both user seller and buyer in e-commerce contribute to increase the sales volume through effective usage to e-commerce.

\subsubsection{Percentage of customer services conducted online}

We asked the participants about their view with regard to the percentage of customer services online and its impact on ecommerce usage by the consumers.

The results showed that ( 0 strongly disagree, 0 disagree, 7 neutral, 46 agree, 27 strongly agree). The results statistics is shown in Figure-6 below: 


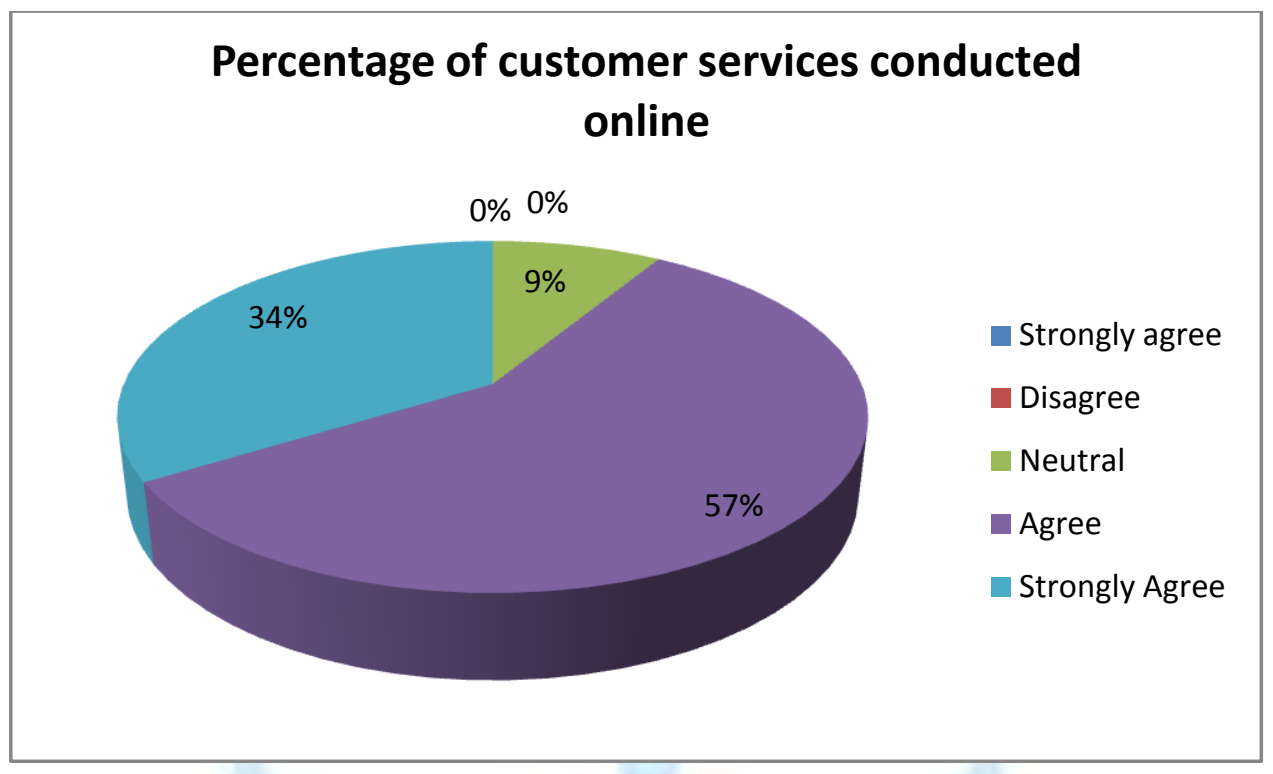

Figure-6: Percentage of customer services conducted online

The result shows that the majority of participants agree and strongly agree that good customer service increase the usage of e-commerce. The mean value equal to (4.2500) which means that the majority of opinions (57\%) confirms the importance of customer service on the number of visits and usage of e-commerce, while standard deviation very small (0.60588), and this means that the study population cluster very close to the mean value (strongly agree).

Companies that sell goods and services online need to make an effort to build value-laden relationships with customers. In other words, a company must look at what customers need and value, and provide it accordingly. Companies that do not provide this expected value will likely lose their customers to a competitor (Kaylene et al., 2008). In addition to that the tourism industry expands globally, hotels expanding their business online need for expanding their communication networks and customer service as well (Hoontrakul \& Sahadev, 2005) and the improvements in customer service can have a significant impact on customer loyalty. In groceries, a one point improvement in customer service satisfaction yielding a significant increase in implied retention rates.

\subsection{Business performance}

The business performance comprises the actual output or results of an organization as measured against its intended outputs (or goals and objectives). According to Richard et al. (2009) organizational performance encompasses three specific areas of firm outcomes: (a) financial performance (profits, return on assets, return on investment, etc.); (b) product market performance (sales, market share, etc.); and (c) shareholder return (total shareholder return, economic value added, etc.). The term Organizational effectiveness is broader. Specialists in many fields are concerned with organizational performance including strategic planners, operations, finance, legal, and organizational development.

In the following section we investigate the relationship between business performance and e-commerce usage:

\subsubsection{The implementation of e-commerce increase customer retention rate}

In the past decade, e-commerce has been known as one of the most important means of doing business in the global market due to the cost and time saving, and also increases the number of loyal customers beyond domestic borders (Hengameh et al., 2012), hence the study examines the impact of e-commerce on business performance through increasing customer retention rate.

We asked the participants whether implementation of e-commerce increase customer loyalty and retention as well as the time the stay online in hotel website.

The results shows that ( 0 strongly disagree, 1 disagree, 3 neutral, 21 agree, 55 strongly agree). The results statistics is shown in Figure-7 below: 


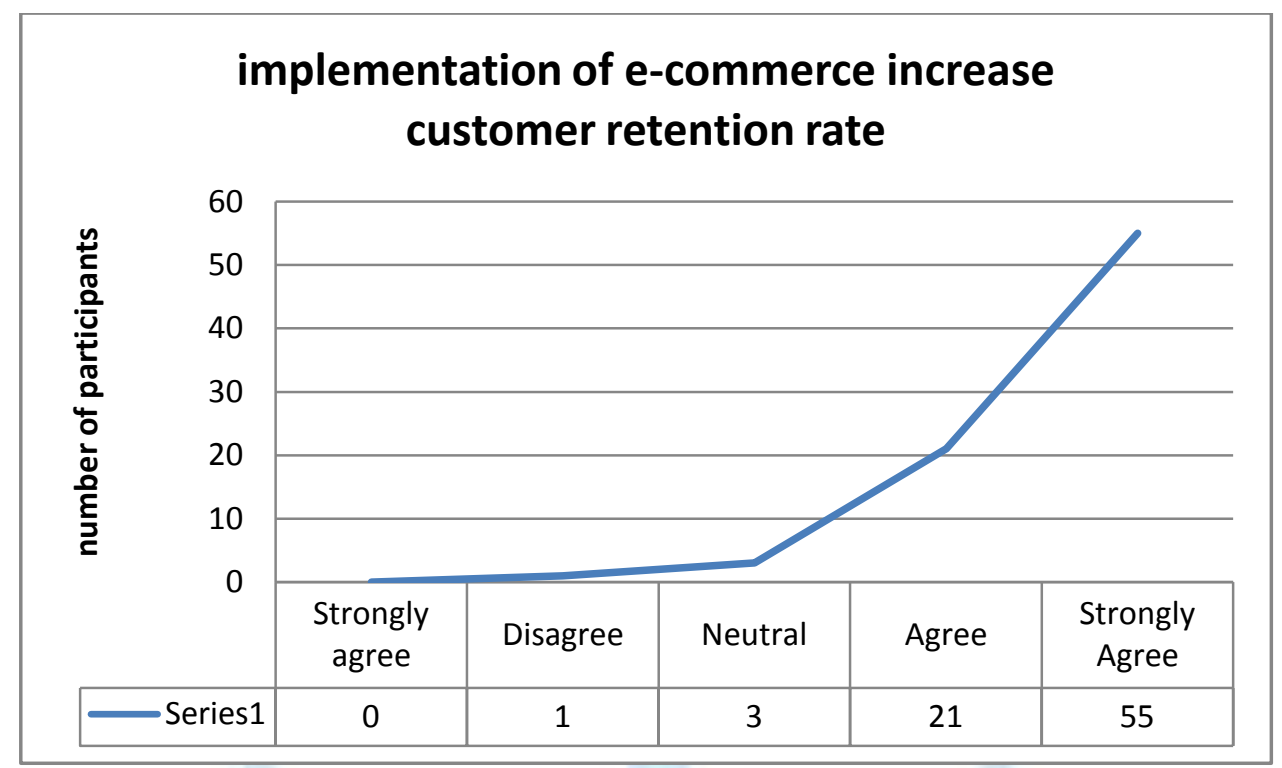

Figure-7: implementation of e-commerce and its impact on customer retention rate

As shown in Figure-7, there is a big increase in participants' percentage who agree or strongly agree with this phrase. The result shows that the vast majority of participants agrees or strongly agrees that implementing e-commerce in hospitality industry in Libya will convert to success through acquiring loyal customers. The mean value equal to (4.6250) and small standard deviation (0.62389) approve the assumption of this study "e-commerce usage has a positive influence on Business performance",

\subsubsection{The implementation of e-commerce increase profitability}

We asked the participants about their opinions with regard to the impact of implementation of e-commerce on increasing the profits of the company.

The results showed that ( 1 strongly disagree, 0 disagree, 3 neutral, 21 agree, 55 strongly agree). The results statistics is shown in Figure-8 below:

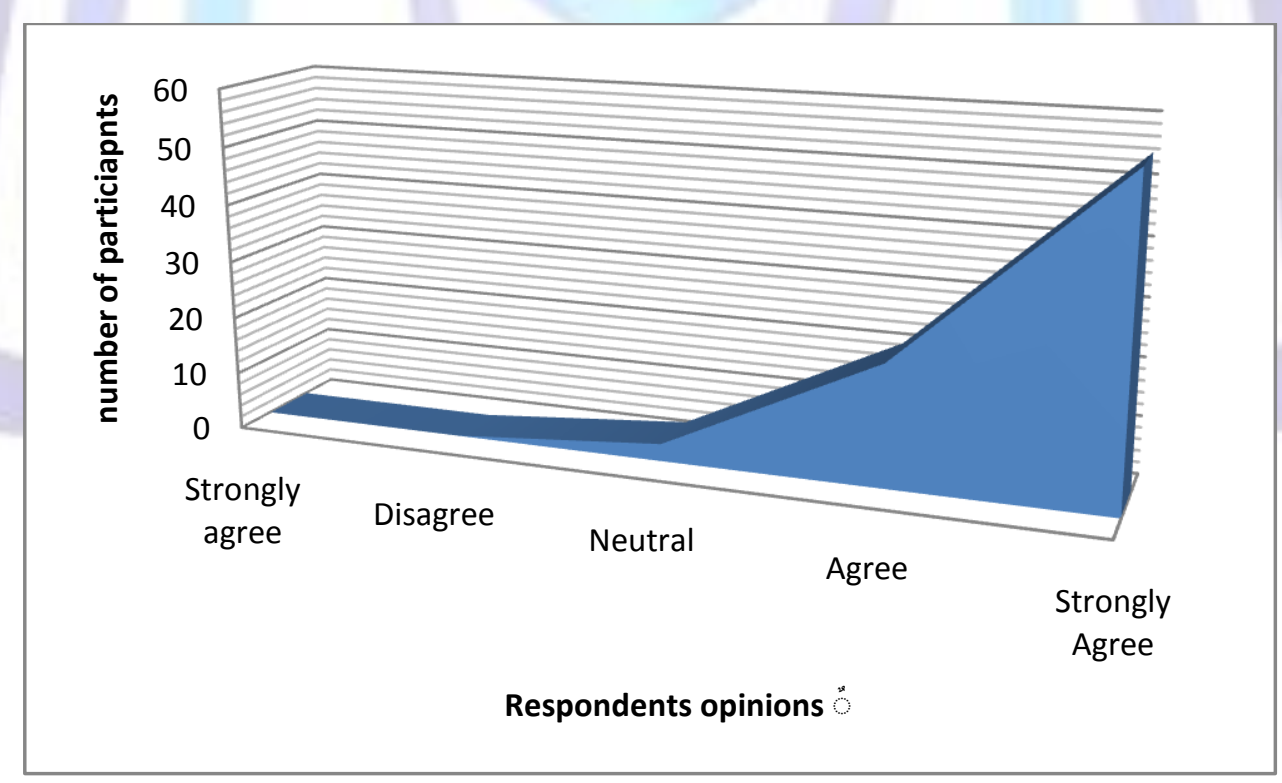

Figure-8: The relationship between e-commerce implementation and profitability

As shown from the figure above that $95 \%$ of the majority of participants are either agreeing or strongly agree on the impact of e-commerce implementation on the profit level of the company. The majority of participants confirmed that adopting ecommerce is reflected positively on the profit of the company. This result shows that hospitality enterprises are expected to achieve significant benefits by way of growth in sales and profits through the increasing utilization of the internet technology through implementing e-commerce (Hoontrakul \& Sahadev, 2005) 


\section{Conclusion}

E-commerce is the most fast developing technology nowadays with a high rate of adoption by firms of all type of business all over the world. The hospitality industry among the main industries that gained great benefits and profits from implementing e-commerce and changed their business strategies to online business model.

Therefore, from the practical perspective, the results of this study assist Libyan hotels sector in formulating new strategies and capitalizing on the benefits of usage promising technologies to manage their business effectively.

The results shows that small and medium size firms in hospitality industry in Libya are facing similar challenges and obstacles to other small businesses when establishing a e-commerce website or attempting to conduct booking online, and they required assistance with basic planning for website implementation and maintenance, consideration of internal and external resources, development of a website marketing strategy and evaluating the website`s success.

In addition to that the study shows a strong relationship between e-commerce usage and business performance, and when hotels implement e-commerce and start to conduct booking online, their annual sales and profits increased significantly.

Finally, the senior managers of hotels in Libya should realize the great importance of e-commerce for their business and must consider it the only way to extend their business globally with high level of profitability and quality performance.

\section{References}

Andriotis, K. (2002). Scale of Hospitality Firms and Local Economic Development. The Case of Crete, TourismManagement,No. 23(4).

American Hotel \& Lodging Association. (2012). Modern capitalist economies are comprised of industrial sectors: Lodging Industry Profile, U.S. Department of Commerce, International Trade Administration, Office of Travel \& Tourism Industries; U.S. Department of Commerce, Bureau of Economic Analysis, Statistics Canada; Banco de Mexico.

Andrew P. Davidson, Stephen Burgess. (2006). E-commerce in tourism, use of website by small regional tourism enterprises, National Library of Australia Cataloguing in Publication Data, publishing: CRC for Sustainable Tourism Pty Ltd.

Andrey Smirnov. 2011. E-Commerce for the Hospitality Industry. The Moscow Times: (http://www.themoscowtimes.com/business_for_business/article/e-commerce-for-the-hospitalityindustry/449373.html\#ixzz2kP9d1vYa)

Bharati, P., \& Chaudhury, A. (2006). Studying the Current Status, examining the extent and nature of adoption of technologies by micro, small and medium-sized manufacturing firms in the greater Boston area. Communications of the ACM, No.49 (10).

Bharat, B., \& Abhijit, B. (2010). Measuring Determinants of E-Commerce Readiness and their Effects on Buying Intention for Online Purchase Decisions. Advances in Management, No. 3(7).

Buhalis, D and Deimezi, O. (2004). E-tourism developments in Greece: Information communication technologies adoption for the strategic management of the Greek tourism industry, Tourism \& Hospitality Research, Vol. 5. No (2).

Damanpour, F. (1991). Organizational innovation: a meta-analysis of effects of determinants and moderators. Academy of Management Journal, 34 (3) 555-90.

Frieden, Jonathan D.; Roche, Sean Patrick. (2006). E-Commerce: Legal Issues of the Online Retailer in Virginia, Richmond Journal of Law and Technology Vol 13 (2).

Karakaya, F., \& Shea, T. (2008). Underlying Motivations for Establishing E-commerce Business and their Realtionship to E-commerce success. Journal of Internet Commerce, No.7(2).

R.C. MacGregor, L. Vrazalic, S. Carlsson, D. Bunker, M. Magnusson. (2002). The Impact of Business Size And Business Type on Small Business Investment In Electronic Commerce: A Study of Swedish Small Businesses, Department of Information Systems, University of Wollongong, Australia, Vol. 9, No. 2.

Richard et al. (2009). Measuring Organizational Performance: Towards Methodological Best Practice. Journal of Management, Vol. 3, No (33).

Shore, B. (2001). Information Sharing in Global Supply Chain Systems. Journal of Global Information Technology Management, No. 4(3), pp. 27-50.

Silviu Vlad Mirescu, Titu Maiorescu University, Bucharest, Romania (2011). The Premises and the Evolution of Electronic Commerce. Journal of knowledge management, economics and information technology

Salwani, M., Marthandan, G., Norzaidi, M. and Chong, S.(2009). E-commerce usage and business performance in the Malaysian tourism sector: empirical analysis. Information Management \& Computer Security, 17 (2)166-185.

Sahadev, S. and Islam, N.(2005).Why hotels adopt ICTs: a study on the ICT adoption propensity of hotels in Thailand, International Journal of Contemporary Hospitality Management, 17(5) 391-401.

Thong, J.Y.L. (1999). An Integrated Model of Information Systems Adoption in Small Businesses. Journal of Management Information Systems, No. 15(4). 
Piergiovanni R., Enrico Santarelli, L. Klomp and Roy Thurik. (2005). Gibrat's Law and the Firm Size / Firm Growth Relationship in Italian Services, New Economics Papers: this item is included in nep-com and nep-ent.

Practices Kaylene C. Williams, Edward H. Hernandez, Alfred R. Petrosky. (2008). Fine-Tuning Useful E-Commerce, Journal of Technology Research, Vol 4, No (15).

Pongsak Hoontrakul, Sunil Sahadev. (2005). Exploring the Determinants of E-Commerce Usage in the Hotel Industry In Thailand: An Empirical Study. Economic Globalization \& the Choice of Asia: Shanghai Forum

Hengameh Rabiei, Mohammad Reza Meigounpoory, Pedram Yazdani, Mostafa Maleki Someah lu. (2011). Key Success Factors for Achieving Customer's Loyalty in E-Commerce: A Study On impact Of Customer and E-Business Characteristics on E-Loyalty in Iran

Pongsak Hoontrakul, Sunil Sahadev. (2005). Exploring the Determinants of E-Commerce Usage in The Hotel Industry in Thailand: an Empirical Study, Economic Globalization \& the Choice of Asia: Shanghai Forum.

Zhu, K. (2004). Information transparency of business-to-business electronic markets: a game-theoretic analysis, Management Science, Vol. 50 No. 5.

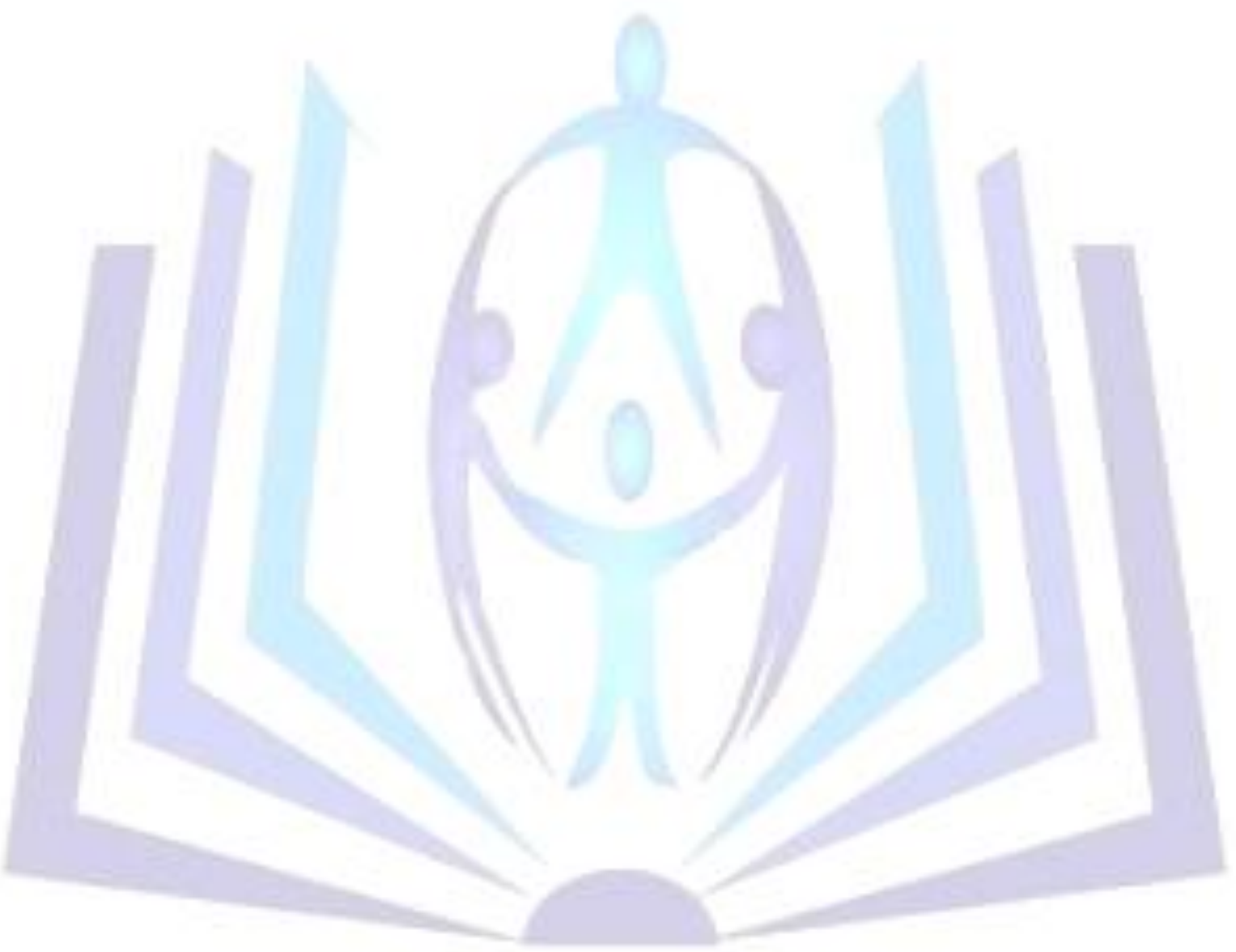

